\title{
A multivariate data approach for FTIR-ATR monitoring of virgin olive oils: Lipid structure during autoxidation
}

\author{
Didar Üçüncüoğlu ${ }^{1, *}$ and Vedat Arda Küçük ${ }^{2}$ \\ ${ }^{1}$ Cankiri Karatekin University, Faculty of Engineering, Department of Food Engineering, 18100 Cankiri, Turkey \\ ${ }^{2}$ Cankiri Karatekin University, Faculty of Engineering, Department of Chemical Engineering, 18100 Cankiri, Turkey
}

Received 30 January 2019 - Accepted 3 October 2019

\begin{abstract}
In this study, fresh and 12 month stored virgin olive oils (VOOs) were monitored with Attenuated total reflectance-Fourier transform infrared spectroscopy (ATR-FTIR) as a quick, nondestructive and no chemical used method. Principal component analysis (PCA) chemometric procedure was used to discriminate those in terms of diversity parameters (cultivar and growing area of olives) and detect possible chemical differences on lipid structure at the end of storage time. In this way, analyses were carried on at the beginning of the storage time and were repeated at the end of the storage time. $1488-924 \mathrm{~cm}^{-1}$ band gave the best (PC1: 98\%) discrimination at the beginning of storage. It was also observed that symmetric and asymmetric stretching vibration of aldehydes, ketones, alcohols and hydroperoxides (3008, 2924, $1745 \mathrm{~cm}^{-1}$ ) were found to be more intense at the end of the storage time. Moreover, $3080-2790 \mathrm{~cm}^{-1}$ band gave the best (PC1: 96\%) discrimination after 12 month expiry. In conclusion, FTIR spectroscopy was demonstrated to be a rapid tool with chemometric evaluation for accurate discrimination of olive oils based on cultivar and geographic origin.
\end{abstract}

Keywords: FTIR / PCA / virgin olive oils / storage / multivariate data analysis

Résumé - Une approche de données multivariées pour la surveillance FTIR-ATR des huiles d'olive vierges: structure des lipides au cours de l'autoxydation. Dans cette étude, des huiles d'olive vierges (VOO) fraîches et stockées durant 12 mois ont été contrôlées par spectroscopie infrarouge à transformée de Fourier à réflexion totale atténuée (ATR-FTIR) en tant que méthode rapide, non destructive et sans produit chimique. Une procédure chimiométrique d'analyse en composantes principales (ACP) a été utilisée pour discriminer les paramètres de diversité (cultivar et zone de culture des olives) et détecter d'éventuelles différences chimiques sur la structure lipidique à la fin de la période de stockage. De cette manière, les analyses ont été effectuées au début de la durée de stockage et ont été répétées à la fin de la durée de stockage. La bande d'absorption 1488-924 $\mathrm{cm}^{-1}$ a donné la meilleure discrimination (PC1 : $98 \%$ ) au début du stockage. Il a également été observé que les vibrations d'élongation symétriques et asymétriques des aldéhydes, des cétones, des alcools et des hydroperoxydes $\left(3008,2924,1745 \mathrm{~cm}^{-1}\right)$ étaient plus intenses à la fin du temps de stockage. De plus, la bande $3080-2790 \mathrm{~cm}^{-1}$ donnait la meilleure discrimination (PC1 : $96 \%$ ) après 12 mois d'expiration. En conclusion, la spectroscopie FTIR s'est révélée être un outil rapide d'évaluation chimiométrique permettant une discrimination précise des huiles d'olive en fonction du cultivar et de l'origine géographique.

Mots clés : FTIR / PCA / huiles d'olive vierges / stockage / analyse de données multivariées / autoxydation

\section{Introduction}

Cultivation of olive trees, production and consumption of table olives and olive oil, as well as assessment of wastes and

*Correspondence: a.emir.57@gmail.com by-products have significant technical and nutritional importance for Mediterranean countries. Thanks to olive oil's chemical composition, including high levels of monounsaturated fatty acid (oleic acid), minor components (biophenols, tocopherols), desired flavour compounds and colour, it is well established as having a large number of positive health effects. Olive oil not only has nutritional and economic impacts but 
Table 1. Sample definitions and label information on package.

\begin{tabular}{llll}
\hline Brand & Cultivar & Geographic origin & Other information \\
\hline 1.A & Ayvalık & Aegean Region (mixture) & Organic; cold press, dark glass bottled EVOO \\
2.B & Ayvalık & North part of Aegean Region (Ayvalıt town, Balıkesir) & Dark glass bottled EVOO \\
3.C & Ayvalık & North part of Aegean Region (Ayvalık town, Balıkesir) & Stone mill; dark glass bottled; PDO signed EVOO \\
4.C & Ayvalık & North part of Aegean Region (Ayvalık town, Balıkesir) & Unfiltered; cold press, dark glass bottled; PDO signed EVOO \\
5.B & Ayvalık & North part of Aegean Region (Edremit town, Balıkesir) & Green-unripe olive extract; transparent glass bottled EVOO \\
6.B & Ayvalık & North part of Aegean Region (Edremit town, Balıkesir) & Well-ripe olive extract; transparent glass bottled EVOO \\
7.B & Ayvalık & North part of Aegean Region (Ayvalık town, Balıkesir) & Dark glass bottled EVOO \\
8.B & Ayvalık & North part of Aegean Region (Cunda Island, Balıkesir) & Dark glass bottled EVOO \\
9.B & Ayvalık & North part of Aegean Region (Edremit town, Balıkesir) & Dark glass bottled EVOO \\
10.B & Ayvalık & North part of Aegean Region (all town mixture) & Dark glass bottled EVOO \\
11.B & Ayvalık & North part of Aegean Region (all town mixture) & Transparent glass bottled EVOO \\
12.B & Memecik & South part of Aegean Region (all town mixture) & Transparent glass bottled EVOO \\
13.C & & & Plastic packed EVOO \\
14.D & & No information & Plastic packed EVOO \\
15.E & Memecik & South part of Aegean Region (all town mixture) & Cold press, transparent glass bottled EVOO \\
16.E & Ayvalık & North part of Aegean Region (all town mixture) & Cold press, transparent glass bottled EVOO \\
\hline
\end{tabular}

also significant social importance such as recitation of olive legends to new generations. Therefore, it can be appropriately referred to as "oleoculture". Consumer perception regarding olive oil can be influenced by many factors such as geographic authenticity, compliance with regulations and special certifications related to olive oil quality. At the same time, these are the most important factors determining the commercial value of olive oils.

Classification, characterisation, detection of adulteration and deterioration of major and minor components of olive oils can be examined using a large range of analytical procedures such as chromatography, spectroscopy or a combination of them (Bajoub et al., 2018). Even though many chromatographic methods such as gas chromatography have been the official techniques utilised, they are really time consuming and involve toxic chemicals. In this assay, a vibrational spectroscopic method termed FTIR was used to classify fresh VOOs and to detect probable storage defects at the end of oils' 12month expiry.

FTIR spectroscopy has many advantages over other spectroscopic analysis methods. First, it gives fast results and its usage is simple. Secondly, sample preparation is easy. All functional chemical bonds give different molecular vibrations and intensities when using FTIR spectroscopy according to their motion type (i.e. stretching, bending, wagging, rocking, scissoring). Evaluation of spectral data requires some of software application with prediction or validation models. FTIR spectroscopy was used by several olive oil researchers for classification (Jimenez-Carvelo et al., 2017), monitoring of adulteration (Rohman et al., 2017), characterisation of cultivars (Abdallah et al., 2016) and geographic origin (Hennessy et al., 2009). Different data processing techniques were applied in these previous studies (Sinelli et al., 2007; Maggio et al., 2009; Lerma-García et al., 2011). Particularly, researchers have focused on the thermal oxidation of VOOs (Selaimia et al., 2017) due to the nutritional and economic losses, and also generation of toxic compounds. However in this study, it was aimed that classifying fresh VOOs based on cultivar and geographic origin, and to improve knowledge including observation of the effects of "slow-pace autoxidation" at room temperature in dark conditions on lipid chemical structure by FTIR spectroscopy using PCA chemometric data mining. To the best of our knowledge, there was no research about autoxidation monitoring of stored VOOs by FTIR without any thermal stress.

\section{Materials and methods}

\subsection{Materials}

16 virgin olive oil brands including "Ayvallk" and "Memecik" cultivars ( $c v$.), which are leading cultivars for oil production in Turkey, were collected from different retail shops (signed as A, B, C, D and E) after the 2017-2018 harvest season on March 2018. Three bottles for each brand package were used and each oil sample bottle was analysed in triplicate $(3 \times 3 \times 16)$, so that the number of analyse sample was 144 .

Brand and label information of VOO samples were also provided in Table 1. It can be seen that there was 1 organicprocessed VOO. The others were obtained from different geographical origins namely "North Aegean Region" and "South Aegean Region".

\subsection{Methods}

The FTIR spectra of every sample was scanned and recorded. Then, all commercial VOOs were stored between $22-26^{\circ} \mathrm{C}$ in dark conditions during 12 months. FTIR analysis was again performed at the end of 12 months storage time.

\subsubsection{FTIR spectroscopic analysis}

After subtraction against air spectra, all VOOs were scanned with an ATR-FTIR spectrometer using OPUS NT 6.0 spectroscopic software (Bruker Tensor II, Bruker Optics Inc., Billerica, Milano, Italy) in the range from 4000 to $400 \mathrm{~cm}^{-1}$ with a resolution of $4 \mathrm{~cm}^{-1}$ at 20 scans and at controlled ambient temperature $\left(20^{\circ} \mathrm{C}\right)$. A low volume of sample $(5 \mu \mathrm{L})$ 
Table 2. FTIR-ATR spectral zones for PCA data evaluation.

\begin{tabular}{|c|c|c|c|c|}
\hline $793-650$ & $\begin{array}{l}-\left(\mathrm{CH}_{2}\right)_{n}- \\
-\mathrm{HC}=\mathrm{CH}-(c i s)\end{array}$ & 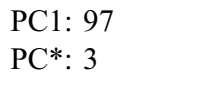 & $\begin{array}{l}\text { PC1: } 86 \\
\text { PC* }^{*} 10\end{array}$ & $\begin{array}{l}\text { Rocking } \\
\text { Bending (out of plane) }\end{array}$ \\
\hline 1488-924 & $\begin{array}{l}-\mathrm{HC}=\mathrm{CH}-(\text { cis }) \\
-\mathrm{C}-\mathrm{O}- \\
-\mathrm{CH}_{2}- \\
-\mathrm{C}-\mathrm{H}-\left(\text { terminal- } \mathrm{CH}_{3}\right) \\
-\mathrm{C}-\mathrm{H}-\left(\mathrm{CH}_{2}\right)\end{array}$ & 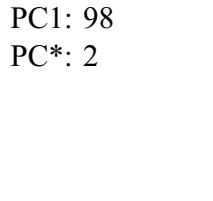 & $\begin{array}{l}\text { PC1: } 89 \\
\text { PC* }^{*} 4\end{array}$ & $\begin{array}{l}\text { Bending (out of plane) } \\
\text { Stretching } \\
\text { Bending } \\
\text { Asymmetric bending } \\
\text { Scissoring }\end{array}$ \\
\hline $1814-1637$ & $\begin{array}{l}-\mathrm{C}=\mathrm{O} \text { (free fatty acids, ester bonds } \\
\text { from triglyceride) } \\
-\mathrm{C}-\mathrm{H}-\left(\mathrm{CH}_{2}\right)\end{array}$ & 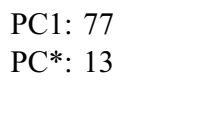 & $\begin{array}{l}\text { PC1: } 66 \\
\text { PC2: } 26\end{array}$ & $\begin{array}{l}\text { Stretching } \\
\text { Asymmetric stretching }\end{array}$ \\
\hline $3080-2790$ & $\begin{array}{l}=\mathrm{C}-\mathrm{H}(\text { cis fatty acid }) \\
=\mathrm{C}-\mathrm{H}(\text { trans fatty acid) } \\
-\mathrm{OH} \text { (hydroperoxides, alcohols })\end{array}$ & $\begin{array}{l}\text { PC1: } 77 \\
\mathrm{PC}^{*}: 12\end{array}$ & $\begin{array}{l}\text { PC1: } 96 \\
\mathrm{PC}^{*}: 3\end{array}$ & Stretching \\
\hline
\end{tabular}

PC*: determines the sum of other PC scores;

*: Silverstein et al., 1981; Guillèn and Cabo, 2000; Maggio et al., 2009; Jiang et al., 2016; Li and Wang, 2018 ; Tena et al., 2018.

was dropped between the well-polished disks for getting a thin film. A deuterated triglycine sulphate detector was used.

The acquisition of FTIR spectra was performed in triplicate and displayed as mean spectra in both absorbance and transmittance mode. The data of each spectrum were obtained by OPUS NT 6.0 spectroscopic software in excel format for further multivariate analysis (PCA).

\subsubsection{Multivariate analysis}

PCA is a statistical test involving factor analysis, which has been accepted as an exploratory method in multivariate statistical analysis and is a mathematical tool which shows variations in the dataset using a small number of factors (Granato et al., 2018). PCA assessment was carried out by Unscrambler software (version 9.7, Camo Company, Oslo, Norway) for statistical analysis. Every obtained data was examined and then, the spectral region was divided at 5 groups. These were 793-650, 1488-924, 1814-1637, 2936-2357 and $3000-2790 \mathrm{~cm}^{-1}$ for fresh VOOs and 793-650, 1488-924, 1814-1637, 2936-2357 and 3080-2790 $\mathrm{cm}^{-1}$ for stored VOOs (Tab. 2). The successful wave number bands for classification in terms of cultivar and geographic origin were given in Table 2 and were discussed above.

\section{Results and discussions}

\subsection{Determination of FTIR spectra}

Characteristic FTIR spectra of VOOs both at the beginning and at the end of storage were shown for the $3600-600 \mathrm{~cm}^{-1}$ region (Fig. 1). The peaks were basically dominated at $\sim 3006$,
2952, 2922, 2873, 2853, 1744, 1463, 1417, 1402, $\sim 1377, \sim 1322, \sim 1305, \sim 1279, \sim 1238, \sim 1160, \sim 1118, \sim 1096$, $\sim 1032, \sim 968$ and $\sim 725 \mathrm{~cm}^{-1}$ wave numbers from "fresh VOOs". The most prominent peaks of "stored VOOs" located at $3006, \sim 2955, \sim 2922, \sim 2853, \sim 1744, \sim 1462, \sim 1236$, $\sim 1160, \sim 1118, \sim 1096, \sim 1062$ and $\sim 1032 \mathrm{~cm}^{-1}$ wave numbers. The detected frequency, their functional bond roots and mode of vibrations were also given at Table 2 and described here.

The peak at $725 \mathrm{~cm}^{-1}$ was explained by the $\mathrm{CH}_{2}$ rocking and $-\mathrm{HC}=\mathrm{CH}-$ (cis) bending mode of molecular vibrations. $1238-1032 \mathrm{~cm}^{-1}$ peak were associated with $-\mathrm{C}-\mathrm{O}-$ stretching and $-\mathrm{CH}_{2}-$ bending movements, while the $1462 \mathrm{~cm}^{-1}$ band arose from $\mathrm{CH}_{2}$ scissoring vibrations. The major peaks at 1744 and $2922 \mathrm{~cm}^{-1}$ could be explained as $\mathrm{C}=\mathrm{O}$ stretching and $\mathrm{CH}_{2}$ asymmetric stretching motions, respectively (Silverstein et al., 1981; Guillèn and Cabo, 2000; Maggio et al., 2009). It could be newly observed in this work that $\sim 2873, \sim 1417, \sim 1402$, $\sim 1377, \sim 1322$ and $\sim 1305 \mathrm{~cm}^{-1}$ peaks disappeared due to fragmentation or derivatization and $\sim 1062 \mathrm{~cm}^{-1}$ peak generated after 12 month storage. It was inferred that some of symmetric stretching, asymmetric and symmetric bending vibrational motion broke down $\left(-\mathrm{C}-\mathrm{H}-\right.$ from $-\mathrm{CH}_{2}$ and terminal carbon atom). On the other hand, the $\sim 1062 \mathrm{~cm}^{-1}$ peak was newly occurred by $-\mathrm{C}-\mathrm{O}-$ stretching movement. Moreover, the 3029-2989 $\mathrm{cm}^{-1}$ band was linked $=\mathrm{CH}$ (both -cis and -trans isomers) and -OH stretching of hydroperoxides and alcohols (Li and Wang, 2018; Tena et al., 2018). Therefore, it could be considered that the band over $2952 \mathrm{~cm}^{-1}$ and $\sim 1062 \mathrm{~cm}^{-1}$ peaks were a fingerprint of the slow-paced autoxidation process. 

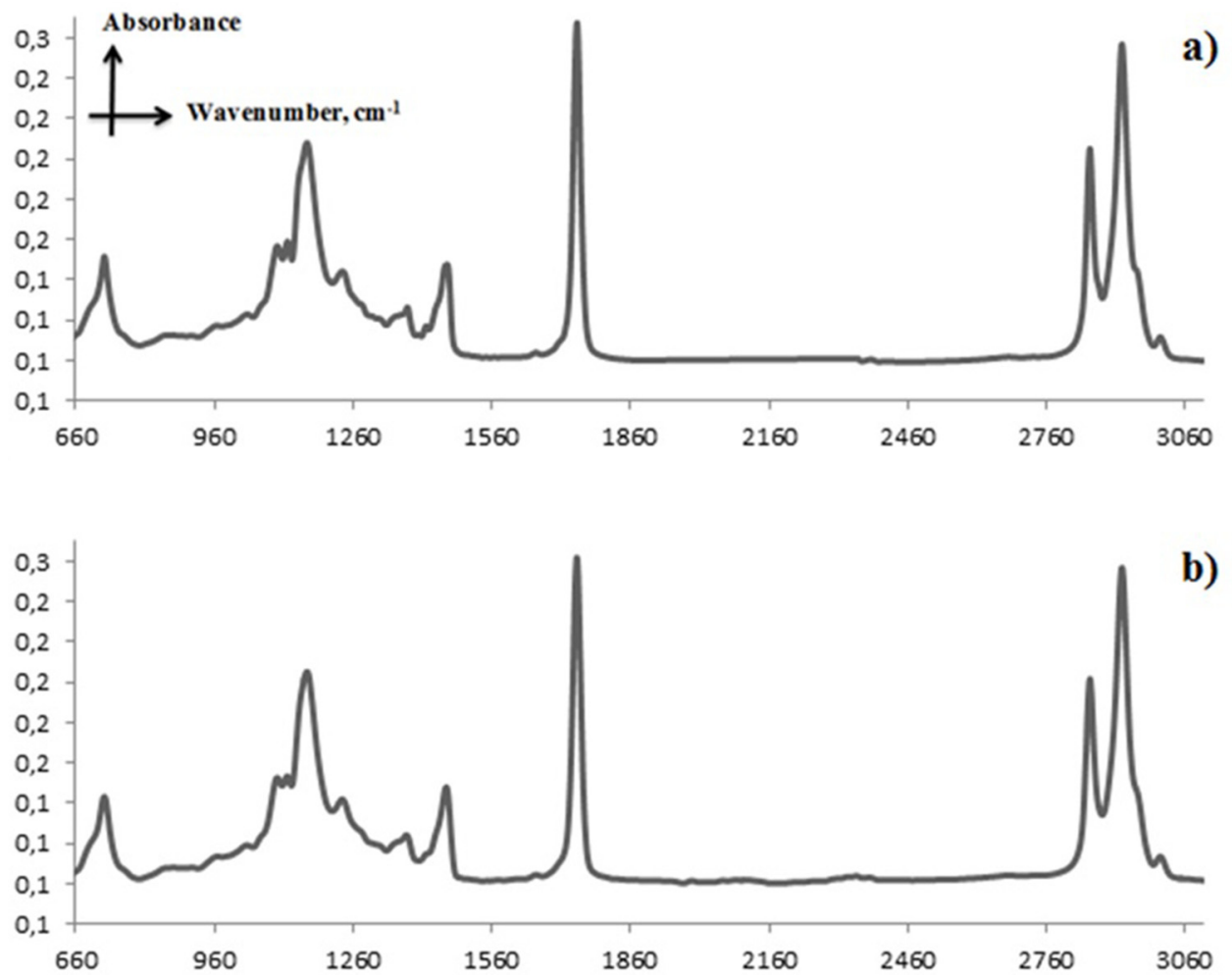

Fig. 1. The characteristic FTIR spectra of VOOs. a: defined as fresh VOOs; b: defined as 12 month stored at room temperature in dark conditions VOOs.

A previous study demonstrated that $1744 \mathrm{~cm}^{-1}(\mathrm{C}=\mathrm{O}$ stretching vibration of aldehydes and ketones), $2922 \mathrm{~cm}^{-1}$ $\left(\mathrm{CH}_{2}\right.$ asymmetric stretching) and $3006 \mathrm{~cm}^{-1}(\mathrm{OH}$ stretching of hydroperoxides) bands could be used for differentiating VOOs in terms of chemical bond vibrational mode. $1463 \mathrm{~cm}^{-1}$ (scissoring mode of $-\mathrm{CH}$ in $\mathrm{CH}_{2}$ ), $1160 \mathrm{~cm}^{-1}$ (stretching of $\mathrm{C}-\mathrm{O}$ and bending of $-\mathrm{CH}_{2}$ ), $1118 \mathrm{~cm}^{-1}$ (stretching of $\mathrm{C}-\mathrm{O}$ ), $1096 \mathrm{~cm}^{-1}$ (stretching of $\mathrm{C}-\mathrm{O}$ ) and $723 \mathrm{~cm}^{-1}$ (rocking mode of $-\left(\mathrm{CH}_{2}\right)_{n}$ and out-of-plane bending mode of cis $-\mathrm{HC}=\mathrm{CH}$ ) bands showed similar loadings at PCA due to the intensity of the functional group (Li and Wang, 2018). The peaks measured at $1363 \mathrm{~cm}^{-1}$ and $1218 \mathrm{~cm}^{-1}$ belong to ether and epoxide structures, respectively, and were not observed to be intense. On the other hand, many "FTIR spectroscopy and storage studies concerning virgin olive oil" have been especially examined in terms of "thermal oxidation". On this direction, it was described before that after heat treatment, some peculiar infrared bands of an olive oil sample were changed (Guillèn and Cabo, 2000). The initial phase of the oxidation involves both the generation and increment of the hydroperoxides. Moreover, the next steps are characterised by the breaking of the ester bonds, which decreases the unsaturation degree and increases -trans isomer concentration (Navarra et al., 2011). For this reason, frequency and absorbance of bands near $3006 \mathrm{~cm}^{-1}$ change when the thermal oxidation process advances (Guillèn and Cabo, 2002).

In this study, PCA was used to differentiate VOOs from two geographical origins (North and South Aegean Region), two olive cultivars (Memecik $c v$. and Ayvalık $c v$.) based on the extracted principal components (PCs). $1488-924 \mathrm{~cm}^{-1}$ band gave the best (PC1: 98\%) discrimination of VOOs by PCA at the beginning of storage. $3080-2790 \mathrm{~cm}^{-1}$ band gave the best (PC1: 96\%) discrimination of VOOs by PCA after 12 month expiry. Therefore, chemometric results were explained in terms of those spectral regions.

\subsection{Principal component analysis}

With the three principal components, $99.69 \%$ of total variance was explained (PC1: $98.2 \%, \mathrm{PC} 2: 1.1 \%, \mathrm{PC} 3: 0.4 \%$ ) according to $1488-924 \mathrm{~cm}^{-1}$ band from fresh VOOs' FTIR data (Fig. 2); and with the three principal components, 99.65\% of total variance was explained (PC1: $96 \%, \mathrm{PC} 2: 3 \%$, PC3: $0.6 \%$ ) according to $3080-2790 \mathrm{~cm}^{-1}$ band from stored VOOs' FTIR data (Fig. 3). Figure 2 showed that three main class, namely 1.A (the organic sample); 12.B and 15.E (Memecik $c v$. from South Aegean Region), and the others (Ayvalik $c v$. from North Aegean Region). After autoxidation at dark conditions, Figure 3 was obtained. It could be observed that 12.B and 15.E (Memecik $c v$. from South Aegean Region), and 3.C and 4.C (PDO signed samples) were clearly categorised.

This study is meaningful for monitoring chemical changes during autoxidation by FTIR analysis with chemometric data evaluation. The promising results could encourage new researches such as nutritional, sensorial and kinetical approach in order to support changes on FTIR spectrum. 


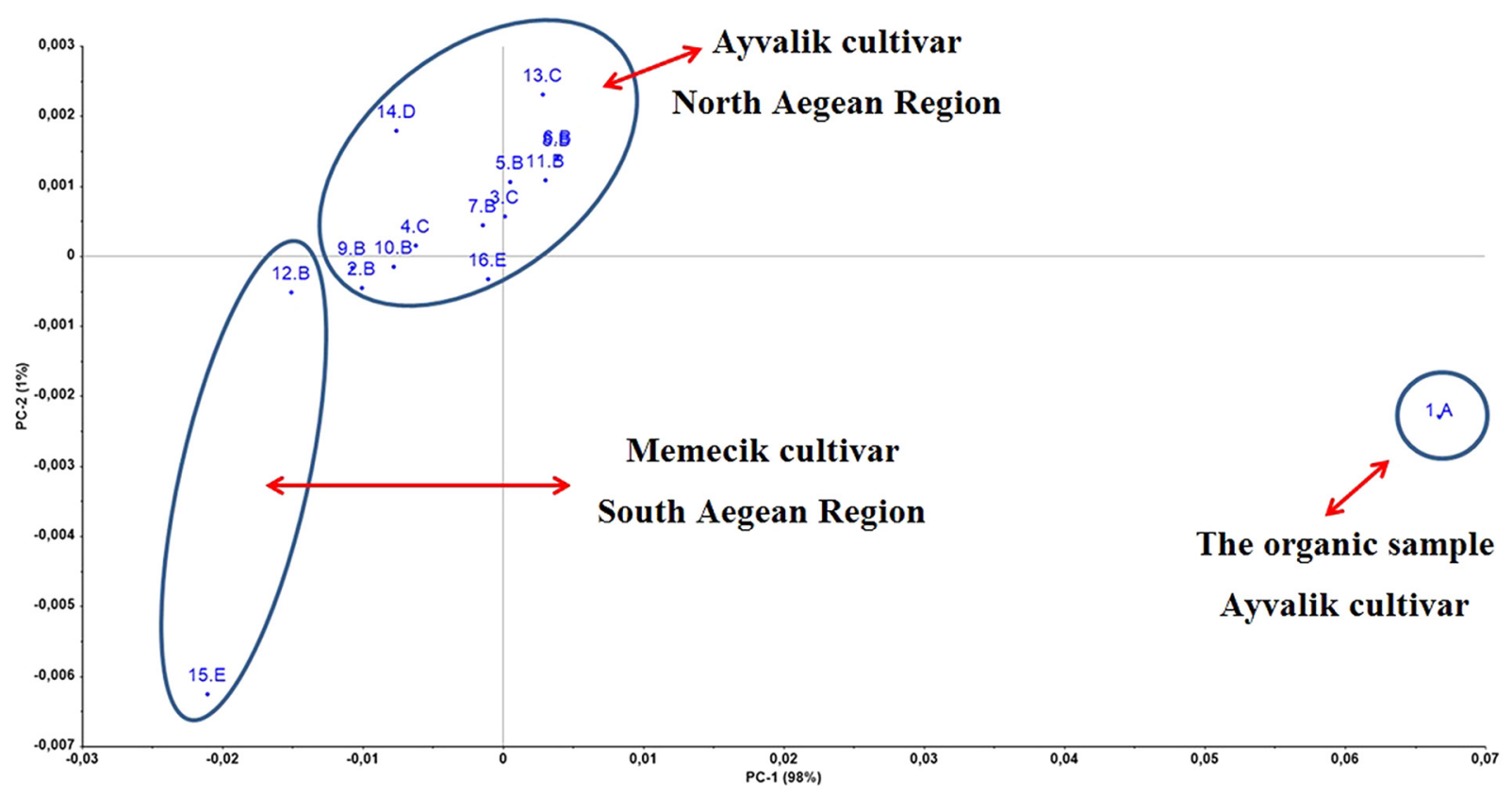

Fig. 2. PCA score plot for initial storage time (fresh VOOs).

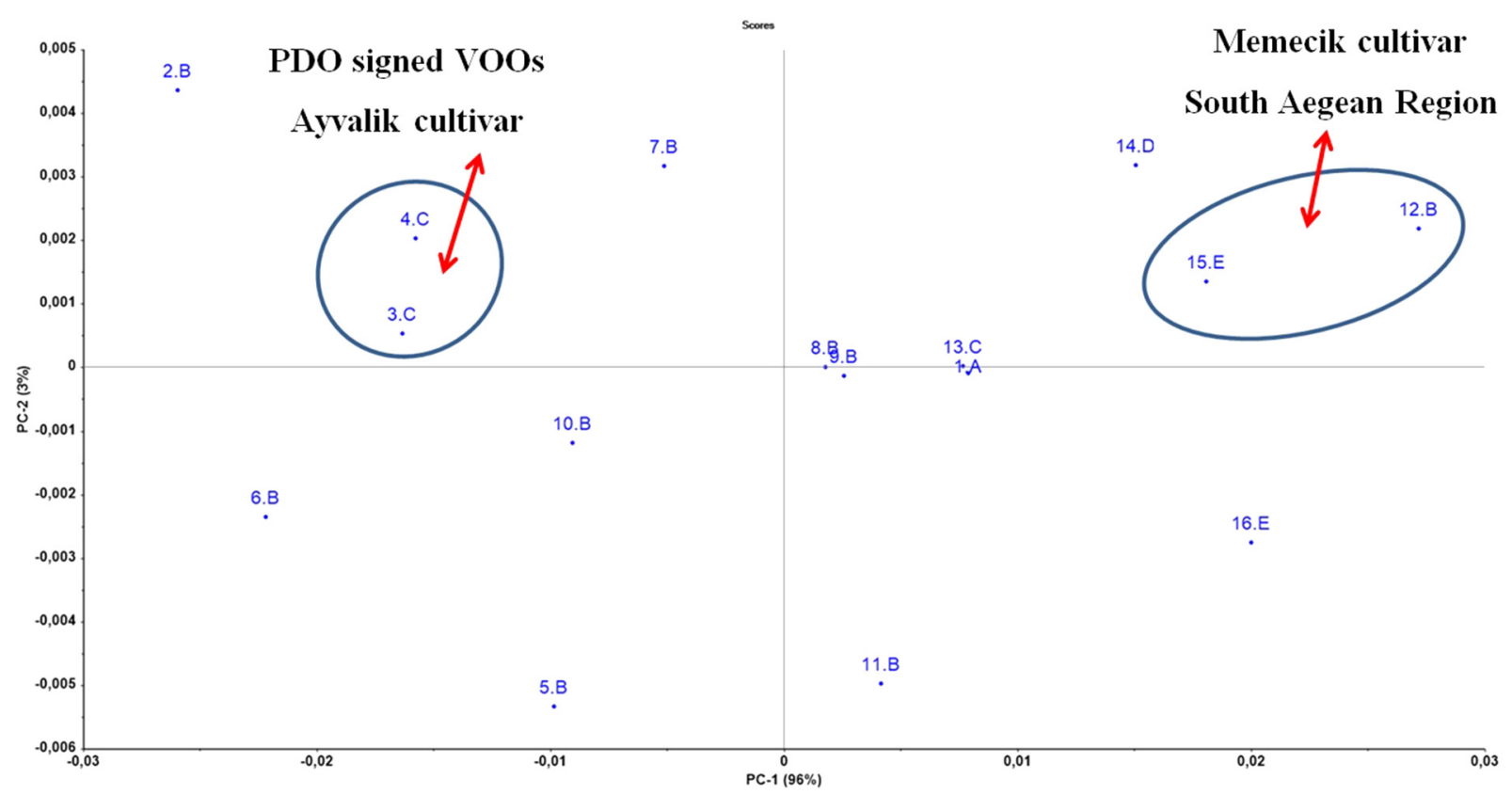

Fig. 3. PCA score plot for the end of storage time (stored VOOs).

\section{Conclusion}

This research concerned with high quality commercial virgin olive oils' vibrational motion monitoring by FTIR with a multivariate perspective. The FTIR fingerprints of virgin olive oils show strong molecular movements and good variability between samples. The discussed results demonstrate that FTIR spectroscopy with PCA tool is able to success for classifying virgin olive oils based on both cultivar and geographic origin.
The potential of FTIR spectroscopy coupled with PCA chemometric model was also determined for stored samples (after 12 months at room temperature in dark conditions in their own package), with the proposed method also being found to be highly appropriate for classifying virgin olive oils. This study also pointed out the advantages of FTIR compared to the long-term official chemical composition analyses. Some of the superiority of FTIR related to its rapidity, nondestructive and low-cost characteristics. 
Acknowledgments. The author heartily acknowledges the Chemical Engineering and Food Engineering Department of Karatekin University for supporting our research.

Conflicts of interest. The authors of the manuscript declare that there is no conflict of interest.

\section{References}

Abdallah M, Vergara-Barberan M, Lerma-Garcia MJ, HerreroMartinez JM, Simo-Alfonso EF, Guerfel M. 2016. Cultivar discrimination and prediction of mixtures of Tunisian extra virgin olive oils by FTIR. Eur J Lipid Sci Technol 118(8): 1236-1242. DOI: $10.1002 /$ ejlt.201500041.

Bajoub A, Bendini A, Fernandez-Gutierrez A, Carrasco-Pancorbo A. 2018. Olive oil authentication: A comparative analysis of regulatory frameworks with especial emphasis on quality and authenticity indices, and recent analytical techniques developed for their assessment. Crit Rev Food Sci Nutr 58(5): 832-857. DOI: 10.1080/10408398.2016.1225666.

Granato D, Santos JS, Escher GB, Ferreira BL, Maggio RM. 2018. Use of principal component analysis (PCA) and hierarchical cluster analysis (HCA) for multivariate association between bioactive compounds and functional properties in foods: A critical perspective. Trends Food Sci Technol 72: 83-90. DOI: 10.1016/j. tifs.2017.12.006.

Guillèn MD, Cabo N. 2000. Some of the most significant changes in the Fourier transform infrared spectra of edible oils under oxidative conditions. $J$ Sci Food Agric 80(14): 2028-2036. DOI: 10.1002/1097-0010(200011)80:14<2028::AID-JSFA713>3.0. $\mathrm{CO} ; 2-4$.

Guillèn MD, Cabo N. 2002. Fourier transform infrared spectra data versus peroxide and anisidine values to determine oxidative stability of edible oils. Food Chem 77(4): 503-510. DOI: 10.1016/S0308-8146(01)00371-5.

Hennessy S, Downey G, O’Donnell CP. 2009. Confirmation of food origin claims by Fourier transform infrared spectroscopy and chemometrics: Extra virgin olive oil from Liguria. J Agric Food Chem 57(5): 1735-1741. DOI: 10.1021/jf803714g.

Jiang X, Li S, Xiang G, et al. 2016. Determination of the acid values of edible oils via FTIR spectroscopy based on the $\mathrm{OH}$ stretching band. Food Chem 212: 585-589. DOI: 10.1016/j.food chem.2016.06.035.
Jimenez-Carvelo AM, Osorio MT, Koidis A, Gonzalez-Casado A, Cuadros-Rodriguez L. 2017. Chemometric classification and quantification of olive oil in blends with any edible vegetable oils using FTIR-ATR and Raman spectroscopy. LWT-Food Sci Technol 86: 174-184. DOI: 10.1016/j.lwt.2017.07.050.

Lerma-García MJ, Simó-Alfonso EF, Bendini A, Cerretani L. 2011. Rapid evaluation of oxidized fatty acid concentration in virgin olive oil using FTIR spectroscopy and multiple linear regression. Food Chem 124: 679-684. DOI: 10.1016/j.food chem.2010.06.054.

Li X, Wang SC. 2018. Shelf life of extra virgin olive oil and its prediction models. J Food Quality 2018: 15. Article ID 1639260. DOI: $10.1155 / 2018 / 1639260$.

Maggio RM, Kaufman TS, Del Carlo M, Cerretani L. 2009. Monitoring of fatty acid composition in virgin olive oil by Fourier transformed infrared spectroscopy coupled with partial least squares. Food Chem 114: 1549-1554. DOI: 10.1016/j.food chem.2008.11.029.

Navarra G, Cannas M, D'Amico M, et al. 2011. Thermal oxidative process in extra-virgin olive oils studied by FTIR, rheology and time resolved luminescence. Food Chem 126(3): 1226-1231. DOI: 10.1016/j.foodchem.2010.12.010.

Rohman A, Man YB, Ismail A, Hashim P. 2017. FTIR spectroscopy coupled with chemometrics of multivariate calibration and discriminant analysis for authentication of extra virgin olive oil. Int J Food Prop 20: 1173-1181. DOI: 10.1080/10942912.2017.1336718.

Selaimia R, Oumeddour R, Nigri S. 2017. The chemometrics approach applied to FTIR spectral data for the oxidation study of Algerian extra virgin olive oil. Int Food Res J 24(3): 1301-1307. Available from http://www.ifrj.upm.edu.my/24\%20(03)\% 202017/(54).pdf

Silverstein RM, Bassler GC, Morrill TC. 1981. Spectrometric identification of organic compounds, 8th ed. New York, USA: John Wiley and Sons. Available from https://www.wiley.com/enus/Spectrometric+Identification + of + Organic + Compounds $\%$ 2C+8th+Edition-p-9780470616376.

Sinelli N, Cosio MS, Gigliotti C, Casiraghi E. 2007. Preliminary study on application of mid infrared spectroscopy for the evaluation of the virgin olive oil freshness. Anal Chimica Acta 598: 128-134. DOI: 10.1016/j.aca.2007.07.024.

Tena N, Aparicio R, Garcia-Gonzalez DL. 2018. Photooxidation effect in liquid lipid matrices: answers from an innovative FTIR spectroscopy strategy with "mesh cell" incubation. J Agric Food Chem 66(13): 3541-3549. DOI: 10.1021/acs.jafc.7b05981.

Cite this article as: Üçüncüoğlu D, Küçük VA. 2019. A multivariate data approach for FTIR-ATR monitoring of virgin olive oils: Lipid structure during autoxidation. OCL 26: 42. 